\title{
Monumentum pietatis. Los epigramas preliminares de fray Tomás López a su hermano Diego López de Valencia de Alcántara. Edición crítica y estudio de fuentes ${ }^{1}$
}

\author{
Abigail Castellano López \\ Fernando Navarro Antolín \\ Universidad de Huelva \\ abigail.castellano@dfesp.uhu.es \\ antolin@dfint.uhu.es
}

Recepción: 25/01/2017, Aceptación: 07/03/2017, Publicación: 22/12/2017

\section{Resumen}

Fray Tomás López, O. P., compuso dos epigramas latinos encomiásticos para los preliminares de sendas obras de su hermano y maestro, el humanista extremeño Diego López de Valencia de Alcántara. Este trabajo aporta un estudio exhaustivo de las fuentes clásicas y del «latín de laboratorio» tan característico de las composiciones latinas de los humanistas del Siglo de Oro, así como un examen de los consabidos tópicos de este tipo de paratextos.

Palabras clave

Diego López; Virgilio; Persio; Alciato; paratextos; epigramas preliminares; latín de laboratorio; humanismo latino

\begin{abstract}
Monumentum pietatis. The preliminary epigrams of Fray Tomás López to his brother Diego López of Valencia de Alcántara: Critical edition and study of sources

Fray Tomás López, O. P., composed two praiseworthy Latin epigrams for the preliminaries of the works of his brother and teacher, the humanist from Extremadura Diego López de
\end{abstract}

1. El presente trabajo se ha financiado con los fondos del Proyecto de Excelencia «Trayectorias europeas del humanismo andaluz: Arias Montano y su entorno ideológico» (HUM-7875) de la Junta de Andalucía, y del Proyecto «Edición crítica, traducción y comentario filológico del De nuptiis Philologiae et Mercurii de Marciano Capela, libros VI-IX: el Quadrivium» (FFI201675840-P) de la DGICYT (Ministerio de Economía y Competitividad). 
Valencia de Alcántara. This work provides an exhaustive study of the classical sources and the "laboratory Latin" so characteristic of the Latin compositions of the humanists of the Spanish Golden Age, as well as an examination of the usual topics of this type of paratexts.

\section{Keywords}

Diego López; Virgil; Persius; Alciato; paratexts; preliminary epigrams; laboratory Latin; Latin humanism

Aunque a menudo se tratara de una mera inercia editorial, la presencia de versos encomiásticos en los preliminares de los libros áureos tuvo con frecuencia la función ańadida de respaldar al autor o vincularlo a círculos de poder y a entornos ideológicos, hasta el punto que la simple ausencia de estos poemas era de inmediato entendida como signo de desamparo y soledad. Baste recordar el ejemplo del primer Quijote y el ataque que, en ese sentido, dirigió contra Cervantes el fingido Alonso Fernández de Avellaneda: «...está tan falto de amigos que, cuando quisiera adornar sus libros con sonetos campanudos, había de ahijarlos — como él diceal preste Juan de las Indias o al emperador de Trapisonda, por no hallar título quizás en España que no se ofendiera de que tomara su nombre en la boca» (Fernández de Avellaneda 2014: 8). Para entonces, a principios del siglo XVII, la poesía compuesta para los preliminares de los libros impresos se constituyó en una suerte de subgénero, cuyas raíces han de buscarse en la producción literaria humanística $y$, en concreto, en el discurso epidíctico del encomio, uno de los catorce ejercicios retóricos que integraban los llamados progymnasmata. ${ }^{2}$

2. Sobre el estudio de los progymnasmata dentro del programa de retórica integrado en los studia humanitatis en la España del Siglo de Oro, véase López Grigera (1993: 585-590); Artaza (1988: 41-55; 2000: 45-66); Asís Garrote (1993: 153-160). 
Un ejemplo extraordinario de ese vínculo humanístico son los poemas que fray Tomás López consagró a dos libros de su hermano, preceptor de gramática latina y maestro de letras humanas. El primero de ellos es Las obras de Publio Virgilio Marón, traduzido en prosa Castellana por Diego López, natural de la Villa de Valencia, Orden de Alcántara, y Preceptor en la Villa de Olmedo, con commento $y$ annotaciones, donde se declaran las historias y fabulas, y el sentido de los versos dificultosos que tiene el Poeta, impreso en Valladolid por Francisco Fernández de Córdova en 1600, según la fecha que aparece en el colofón, o en 1601, según figura en la portada. Tras el «Prólogo al Lector», figura como único poema preliminar un epigrama neolatino con nueve dísticos elegíacos firmado por fray Tomás López, de la orden de Predicadores, que se presenta en el título como «hermano del autor» (fratris auctoris).

En 1615, Diego López publicó otro comentario destinado a ser igualmente un éxito editorial, ${ }^{3}$ la Declaración magistral sobre las Emblemas de Andres Alciato, con todas las Historias, Antigüedades, Moralidad y Doctrina tocante a las buenas costumbres, impreso esta vez en Nájera por Juan de Mongastón. Arropan la obra desde sus preliminares seis poemas laudatorios, compuestos por cuatro sonetos y unas décimas en lengua castellana que se dirigen uno tras otro «al autor, a su maestro». ${ }^{4} \mathrm{El}$ sexto, sin embargo, es el único que opta por el latín como lengua de composición. Se trata de un epigrama en 10 dísticos elegíacos, que firma una vez más fray Tomás López, identificado ahora no solo como "hermano", sino también como "discípulo del autor» (fratris discipulique auctoris). Dado el carácter marcadamente didáctico de la obra, es más que plausible que los autores de los poemas preliminares que encabezan esta edición de 1615 sean discípulos del Maestro Diego López, ${ }^{5}$ autor y, por esta vez, también editor del volumen; en tanto que dan testimonio práctico de que los ejercicios retóricos de composición literaria, a partir de los cuales se instruía al joven estudiante en la formación de su criterio estético, eran un hecho dentro del programa pedagógico de los studia humanitatis. Dicho de otro modo, esta serie de poemas encomiásticos vendrían a ser un testimonio práctico de las excelencias de Diego López como maestro, ya que cabe interpretarlos como ejercicios retóricos de composición literaria, con los que el estudiante, al tiempo que alaba a su profesor, plasma de manera brillante y fehaciente el aprendizaje de tales ejercicios en las clases de Retórica, disciplina integrada en el estudio de las Humanidades.

3. Para una breve reseña de la vida y obras de Diego López, así como una bibliografía sucinta, véase Izquierdo (2012: 495-497).

4. Estos cinco discípulos son: Antonio de la Baria y Cangas, Francisco Cevallos, el licenciado frey Álvaro de Ulloa Paredes, «del hábito de Alcántara», el licenciado frey Francisco de Sotomayor, «del hábito de Alcántara, y, por último, Juan de Mongastón, hijo del impresor de Diego López. Reproduce estos poemas laudatorios (Marsá 2003: 1253-1272; nos. 1, 8, 22, 34 y 37).

5. Sobre la poesía latina compuesta por Diego López, véase Merino (1987: 229-243; 2009: 219241). 
Ambos epigramas preliminares contienen los consabidos tópicos de los poemas laudatorios que encabezan las ediciones de libros, ${ }^{6}$ y que, por lo general, se circunscriben, en primer lugar, al encomio del autor, del que se suele ensalzar su erudición, su mérito y su esfuerzo, y, en segundo lugar, al elogio del libro, atendiendo generalmente a la utilidad de su contenido. Junto a estos dos apartados tampoco falta la consabida exhortación al lector para que lea el libro, pero que lo lea entero, y lo lea con buen talante, conocida por la retórica como captatio benevolentiae.

Fray Tomás López, sin embargo, no se limitó a repetir los lugares comunes del género. Para empezar, el tópico del elogio del autor se desdobla. Al tratarse ambas obras de un comentario —o mejor, de una 'Declaración magistral'-, al elogio del autor de la obra 'declarada' se suma aquí el elogio del autor de la 'declaración'; es más, en el epigrama del Alciato, Tomás López introduce una rivalidad o emulación entre ambos autores: si el autor de la obra original, Alciato, mereció la gloria por sus méritos, pareja gloria merece su comentarista, Diego López; y Virgilio es más universal gracias a Diego López; ambos, Virgilio y Alciato, deben mucho de su éxito a Diego López.

Otro dato de interés, y esto se aprecia sobre todo en el epigrama del Virgilio, es el grado de implicación y proyección personal del epigramatista, que irrumpe en el epigrama y es coprotagonista. Tomás López se presenta repetidas veces como discípulo de su hermano, al que califica, también reiteradas veces, de 'maestro', no disimula su orgullo y admiración, y aunque asegura: fraternus amor non vincit, es evidente que reivindica la obra de Diego López con verdadera pasión de hermano. Tomás López reclama, además — y esto es lo más novedoso-, su porción de gloria. Reclama con orgullo, no exento de vanagloria, que es gracias a su mediación — me medio (v. 3) - que se acaba publicando, por fin, la tan esperada obra. Había como un runrún, una demanda o expectación que reclamaba la publicación de la obra, que no serían más que anotaciones para uso personal de Diego López durante su magisterio. Estamos ante una variante del tópico encomiástico de la obra en ciernes, que tanto evoca la expectación que suscitaba la Eneida de Virgilio según Propercio: «iCeded, autores romanos! ¡Ceded, griegos! / Nace algo más grande que la Ilíada».7 El propio Diego López aludirá a una demanda similar en el «Prólogo al Lector» de su Declaración magistral de las Sátiras de Persio:

Forzado con los ruegos de algunos amigos que vieron esta declaración magistral, hecha sobre las Seis Sátiras de Persio, no con propósito de sacarla a luz, sino solamente para entenderlas para mí solo, hube de publicarla, aunque muchas veces me excusé

6. Sobre la práctica codificada ya en el Siglo de Oro de ańadir poemas encomiásticos en loor del autor de la obra, cf. Güell (2009: 34-35).

7. Cf. Propercio, Elegías II 34, 65-66, Cedite Romani scriptores, cedite Grai! / Nescio quid maius nascitur Iliade. 
diciendo que era materia digna de otro ingenio más agudo, más limado y más sutil que el mío. (Burgos, 1609)

En cuanto al apartado del elogio de la obra, en primer lugar destaca el tópico encomiástico de la universalidad y eternidad de la obra, que, gracias a la labor de Diego López, llegará más lejos, como es el caso de Virgilio, ${ }^{8}$ y perdurará por siempre, en lo que corresponde al caso de Alciato. ${ }^{9}$ Pero hay dos líneas concretas sobre las que Tomás López insiste en estos dos epigramas, y que tienen que ver con la naturaleza misma de los comentarios de Diego López. La primera de ellas es la claridad que la labor del traductor y comentarista ańade al original, esto es, su capacidad para poner en claro lo que estaba oscuro, ya que se trata, como rezan los títulos de ambas obras, de 'Declaraciones'. El léxico de Tomás López (clarus, patefacere, callere, luce clarius, etc.) y las imágenes plásticas (el resplandor del sol que ilumina la oscuridad, el laberinto de Creta desvelado) respaldan y potencian esta idea. La segunda línea de elogio es la moralidad, pues se trata de entender bien a Virgilio, un autor pagano, para enseñarlo correctamente. Esto enlaza con la idea de cristianizar a Virgilio, siguiendo la tradición secular cristiana del Maronem mutatum in melius. El comentario de Virgilio pretende ser un manual escolar para uso del maestro que explica correctamente Virgilio a sus alumnos, esto es, conforme a la moral de la doctrina cristiana. ${ }^{10}$ Aquí también la idea se ve respaldada por el léxico usado en el epigrama: dogmata vera, callere Maronem, exponere carmina vere, callebunt omnes... Maronem. En cuanto al comentario de Alciato, el subtítulo añadido por Diego López al título de Declaración magistral es revelador de esa idea moralizadora: con... Moralidad y Doctrina tocante a las buenas costumbres. Por ello, Tomás López subraya el docere como elemento esencial y casi único de la obra, insistiendo, como veremos, en que el libro contiene cosas provechosas y ejemplos útiles para todo el mundo.

La "Aprobación» de la Declaración de las emblemas de Alciato, salida nada menos que de la pluma del humanista jesuita Juan Luis de la Cerda, resume bien las dos ideas-fuerza de este apartado del elogio del contenido del libro, a saber, claridad y moralidad:

No hallo cosa que repugne a nuestra Santa Fe Católica, ni a las buenas costumbres, antes mucha erudición y moralidades sacadas muy a propósito, de que gustarán mucho los aficionados a letras humanas, y todos podrán entender las Emblemas de Alciato con mucha facilidad por la gran claridad con que el autor las declara.

8. «En adelante el vate recorrerá el orbe, esclarecido» (Virgilio, v. 9).

9. «Ninguna página de este libro envolverá pimienta o incienso, / sino, antes bien, se leerá por muchísimos siglos» (Alciato, vv. 3-4).

10. «El maestro, cuando lo lea (scil. Virgilio), que añada también esta obra (scil. Diego López)» (Virgilio, v. 10). 


\section{Los textos de fray Tomás López y su comentario}

Pero vayamos ya a los textos del poeta dominico y a su traducción, comenzando por el epigrama que abre la obra de Virgilio:

Epigramma fratris Thomae Lopez, Ordinis Praedicatorvm atqve fratris AVTORIS, IN QVO PETIT VT HOC OPVS EDAT.

Ad me confugiunt, doctum callere Maronem qui cupiunt, edas, ut precer ipse, cito.

Desine, me medio, frater, quod gaudeat orbis hoc libro, scripsit quem tua docta manus.

Hoc opus ede cito, frater; quid detinet illud?

Rumpe moras; tribuat doctus Apollo iubar.

Dum librum retines, retinentur dogmata vera; hunc si depromis, dogmata clara manent.

Clarus deinceps vates percurret in orbem, praeceptorque legens sumat et istud opus.

Quo poterit pueris exponere carmina vere; si fuerit doctus, doctior esse potest.

Callebunt omnes, frater, te auctore, Maronem; nam clarus manet luce poeta magis.

Vera cano; fraternus amor non vincit, ut ista eloquar. Hoc meritus, quod patefecit opus.

Quod dignum est tantum, carissime, nomine, frater, ingenio, calamo, more, labore tuo.

Epigrama de Fray Tomás López, de la Orden de Predicadores y hermano DEL AUTOR, EN EL QUE LE PIDE QUE PUBLIQUE ESTA OBRA.

A mí acuden quienes desean entender bien al docto Marón, para que yo te suplique que lo publiques pronto.

Deja, hermano, que, por mediación mía, el orbe goce de este libro que escribió tu docta mano.

Publica pronto, hermano, esta obra. ¿Qué lo impide?

No te demores. Que el docto Apolo arroje luz.

Mientras retienes el libro, se retienen las enseńanzas verdaderas; si lo publicas, las enseñanzas quedan claras.

En adelante el vate recorrerá el orbe, esclarecido, y el maestro, cuando lo lea, que añada también esta obra. 10

Con ella podrá explicar con acierto los versos a los niños; si fuere docto, puede ser más docto.

Bajo tu magisterio, hermano, todos entenderán bien a Marón; pues el poeta queda más claro que la luz.

Verdad digo; no me mueve el amor fraterno a hablar así. Hizo méritos, porque aclaró la obra.

La obra solo es digna de renombre, queridísimo hermano, merced a tu ingenio, cálamo, voluntad y esfuerzo. 
Por lo que parece, se trata de una obra más bien juvenil, en la que los ecos clásicos son más contenidos. Aun así, destaca la presencia de Horacio (v. 5, quis detinet - Hor. Ep. I 25, nisi quid te detinet, audi), del propio Virgilio (v. 6, rumpe moras - Verg. Aen. IV 569; IX 13; Ge. III 42-43) ${ }^{11}$ y de Tibulo (v. 15, vera cano - Tib. II 5, 63). El símil de Apolo, en su doble condición de astro Sol y de dios de las artes y la poesía (v. 6, tribuat doctus Apollo iubar), le sirve para subrayar la labor erudita y declaratoria de Diego López.

Muy otro es el caso del siguiente epigrama, el consagrado a la Declaración de Alciato. Entre uno y otro han pasado tres lustros, y se observa un salto cualitativo importante. Se percibe ahora una mayor complejidad y gusto más visible por el artificio retórico. Es aquí donde mejor se detecta ese «latín de laboratorio» - como lo definió el profesor Maestre- ${ }^{12}$ tan característico de los humanistas. Los calcos textuales y contextuales —e incluso métricos- así lo delatan. ${ }^{13}$

Fratris Thomae Lopez, Ordinis Praedicatorvm, fratris discipvliqve avctoRIS CARMEN.

Hic liber est dignus cedro levique cupresso servandus; scombris tegmina nulla dabit.

Cuius nulla libri piper aut thus pagina volvet, plurima sed potius saecla legendus erit.

Prosunt pauperibus, locupletibus omnia prosunt, 5 et pueris, senibus, quae tenet istud opus.

Nullus erit tandem, lecto qui fronte serena non exempla queat commoda ferre libro.

In quo non auctor curat simulare cupressum, ad tempus dicit frater et omne meus.

Pone supercilium, lector, cum legeris, ergo; perlege, sunt creta cuncta notanda quia.

In Creta Alciatus fuerat labyrinthus ut alta, Daedalus ast frater iam patefecit eum.

Quicquid enim obscurum dixit, meus ecce magister explicat, ut clarum quisque tenere queat.

Non plus Alciato debetur, quam tibi, frater;

11. La juntura virgiliana rumpe moras se hizo enseguida muy célebre y son numerosos los autores latinos que se hacen eco de ella; cf. Ovidio, Heroidas XII 47-48, omnem / pelle moram; Metamorfosis XV 583; Séneca, Troyanas 681; Medea 54; Lucano, Farsalia I 264; II 525; Marcial, Epigramas II 64, 9; Plinio el Joven, Epistolas V 11, 2; Silio Itálico, Púnicas VIII 214-215. Idéntico éxito conoció en siglos posteriores, tanto entre los poetas neolatinos, como entre los vernáculos; basten como ejemplo Julio César Stella (Columbeis I 144) y Luís de Camôes (Os Luisiadas III 105, rompe toda a tardança, acude cedo).

12. Sobre la tipología de los calcos y, en definitiva, sobre el latín de laboratorio de las composiciones latinas de los humanistas, cf. Maestre (1982: 262-263; 1985: 325-340, 1987: XLVI-LV; 1990: 345-364).

13. Como norma, se ponen en cursiva los calcos textuales (totales o parciales) y se subrayan los calcos contextuales. En negrita se destaca el calco métrico. 
gratia par vobis est referenda simul.

Nam Alciatus meruit multum si Emblemata scribens, qui declarat eum, non minus ille meret.

Epigrama de Fray Tomás López, de la Orden de Predicadores, hermano y DISCÍPULO DEL AUTOR.

Este libro es digno del aceite de cedro y de ser guardado en pulido ciprés; no dará envolturas a las caballas.

Ninguna página de este libro envolverá pimienta o incienso, sino, antes bien, se leerá por muchísimos siglos.

Son provechosas para pobres y ricos, para niños y viejos, todas las cosas que contiene este libro.

Nadie habrá, en fin, que, leído el libro con frente serena, no pueda sacar ejemplos útiles.

En él el autor no se ocupa de remedar un ciprés, y mi hermano todo lo dice en sazón.

Depón, pues, el ceño, lector, cuando lo leas; léelo entero, porque todo es digno de marcar con tiza.

Fue Alciato como el laberinto en la alta Creta, pero mi hermano, cual Dédalo, ya lo desveló.

En efecto, lo que aquel dijo oscuro, he aquí que mi maestro lo explica, para que cualquiera pueda tenerlo claro.

No se debe más a Alciato que a ti, hermano; a ambos, a la vez, hay que daros las gracias por igual.

Pues si Alciato tuvo mucho mérito por escribir los Emblemas, aquel que le pone en claro, no tiene menos mérito.

El arranque mismo del epigrama (vv. 1-4: Hic liber est dignus cedro levique cupresso / servandus; scombris tegmina nulla dabit. / Cuius nulla libri piper aut thus pagina volvet / plurima sed potius saecla legendus erit) ${ }^{14}$ es una buena muestra de ese gusto humanístico por el alarde de lecturas y saberes. Con una técnica cuasicentoniana — aunque sin intención paródica-, Tomás López contamina diversas fuentes clásicas, en especial Horacio y Persio, pero también Catulo y Marcial:

- Hor. Ars 331-332, speremus carmina fingi / posse linenda cedro et levi servanda cupresso. ${ }^{15}$

- Pers. I 41-43, an erit qui velle recuset / os populi meruisse et cedro digna locutus, / linquere nec scombros metuentia carmina nec thus? ${ }^{16}$

14. «Este libro es digno del aceite de cedro y de ser guardado /en pulido ciprés; no dará envolturas a las caballas. / Ninguna página de este libro envolverá pimienta o incienso, / sino, antes bien, se leerá por muchísimos siglos.»

15. «(Una vez poseídas las mentes por el afán de lucro) ¿Podemos esperar acaso que sean capaces de componer poemas dignos de ser untados con aceite de cedro y guardados en pulido ciprés?»

16. "¿Acaso habrá quien diga que él no quiere merecer andar en boca del pueblo, y, habiendo dicho cosas dignas del cedro, dejar versos que no temen ni a las caballas, ni al incienso?» 
- Catul. XCV 7-8, Volusi Annales... / et laxas scombris saepe dabunt túnicas. ${ }^{17}$

- Mart. III 2, 1-5, cuius vis fieri, libelle, munus? / Festina tibi vindicem parare, / ne nigram cito raptus in culinam / cordylas madida tegas papyro / vel turis piperisve sis cucullus. / Faustini fugis in sinum? Sapisti. / Cedro nunc licet ambules perunctus. ${ }^{18}$

- Mart. IV 86, 6-11, (Apolinar) si te pectore, si tenebit ore, / nec ronchos metues maligniorum / nec scombris tunicas dabis molestas; / si damnaverit, ad salariorum / curras scrinia protinus licebit, / inversa pueris arande charta. ${ }^{19}$

- Erasmo, Adagios, «Digna cedro». ${ }^{20}$

Todos estos pasajes-fuente, y otros que veremos que son fuentes del resto del epigrama, tienen que ver con la crítica literaria, con motivos como la buena o mala acogida de un libro, con el mecenas protector y las burlas y mofas de los maligni, y con el éxito o fracaso de la obra literaria, visualizado todo ello con imágenes plásticas tan potentes como el aceite de cedro y la caja de ciprés para simbolizar el brillante destino de la obra que perdurará en el tiempo, o la asquerosa envoltura de pescado y el humilde cucurucho de pimienta para estigmatizar el patético final del libro nacido muerto.

Sin duda Tomás López conocía bien estas fuentes clásicas que cita. ¿Pero las conocía porque había leído las Epistolas de Horacio o los Epigramas de Marcial? ¿Son fruto de un rastreo de fuentes, o las sacó de alguna poliantea, thesauro o una cornucopia? La respuesta es bien sencilla: su poliantea era su propio hermano. Tomás López conocía estos pasajes bien por asistir a las clases de su hermano o - lo más probable — por la lectura de la Declaración magistral de las Sátiras de Persio, ${ }^{21}$ publicada pocos años atrás (1609). De allí sacó sus citas, en concreto del pasaje donde Diego López comenta Persio I 41-43:

17. «Los Anales de Volusio... darán a menudo amplias envolturas a las caballas.»

18. «¿En el regalo de quién quieres, libro, convertirte? / Date prisa en procurarte un defensor, / no sea que, llevado de pronto a negra cocina, / envuelvas boquerones con tu papel mojado / o seas un cucurucho de incienso o pimienta? / ¿Huyes al regazo de Faustino? Eres sabio. / Ahora puedes andar untado de cedro...»

19. «Si (Apolinar) te acoge en su pecho o en sus labios, / no tendrás que temer las burlas de los malintencionados, / ni darás penosa envoltura a las caballas. / Si te condena, deberás correr enseguida a las cajas de los pescaderos, / página que los críos garabatearán por el dorso.»

20. Cf. Des. Erasmus Rotterodamus, Adagiorum chiliades quattuor, Secundus Tomus, Basileae, ex officina Frobeniana, 1540, Chiliadis Quartae Centuria I, LIIII, «Digna cedro», p. 872; cf. Emanuele Lelli, Erasmo da Rotterdam. Adagi, Milano: Bompiani (2013: 2208), Centuria $31, \$ 3054$.

21. Sobre esta obra de Diego López, véanse los trabajos de Filomena Fortuny Previ (1999: 153170; 2000: 321-337; 2006a: 717-731; 2006b: 733-748). 
Esto entendió Marcial cuando hablando con su libro le dijo: «Necesario es que agora andes untado con cedro»; y Horacio, aludiendo a esto, dijo en el Arte Poética: «Esperamos que se compondrán versos que puedan ser untados con cedro». De aquí, dijo Erasmo en un adagio: Digna cedro, por «las cosas que deben y son dignas de durar mucho tiempo»... Parece esto algarabía, decir que los versos no temen los alaches ni el incienso, pero, declarado, es lugar curioso... Y así debemos de saber que scombrus significa un pez llamado alache que es género de peces pequeños; y los que los vendían hacían envoltorios de ellos en papeles que tenían en poco; y dice Persio: "Estos versos no temen que se hagan de ellos envoltorios para vender los alaches»... De esta manera de hablar usó Catulo, diciendo: Et laxas scombris saepe dabunt tunicas; y Marcial: Nec scombris tunicas dabis molestas.

Todos los pasajes citados por Diego López aparecen en el arranque del epigrama de Tomás López, quien los tomó del comentario a Persio de su hermano, y no de Erasmo, que solo recoge tres de ellos en sus Adagios (Hor. Ars 331-332; Pers. I 42-43; Mart. III 2, 3-4). Por otra parte, Tomás López, y no es casualidad, no se hace eco de un pasaje horaciano que tiene que ver igualmente con la mala acogida de un libro y su mísero destino final (Hor. Ep. II 1, 267-270): una / cum scriptore meo, capsa porrectus operta, / deferar in vicum vendentem thus et odores / et piper et quicquid chartis amicitur ineptis. ${ }^{22}$ Sin duda porque tampoco lo cita Diego López, que acaso no entendió la metáfora del cortejo fúnebre.

En los versos 5-6, «Prosunt pauperibus, locupletibus omnia prosunt, / et pueris, senibus, quae tenet istud opus», ${ }^{23}$ se adapta la conocida exhortación o invitación universal de Horacio al cultivo de la Filosofía en Epistolas I 1, 25-26: Aeque pauperis prodest, locupletibus aeque, / aeque neglectum pueris senibusque nocebit. ${ }^{24}$ Horacio, a su vez, pudo tomar esta exhortación de la Epistola a Meneceo de Epicuro, según la transmite Diógenes Laercio (X 122): «Deben filosofar

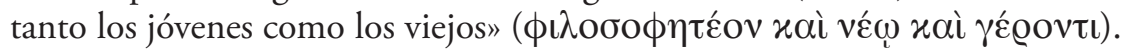

Por su parte, los versos 7-8, «Nullus erit tandem, lecto qui fronte serena / non exempla queat commoda ferre libro", ${ }^{25}$ evocan Mart. VIII 12, 1-2: Sic me fronte legat dominus, Faustine, serena / excipiatque meos qua solet aure iocos. ${ }^{26}$ Nuevamente volvemos en estos versos a los tópicos que tienen que ver con la crítica literaria, con la buena o mala acogida del libro por parte del lector y con la figura del mecenas protector frente a las malas críticas de los maligni. Algo similar ocurre con el dístico 9-10, «In quo non auctor curat simulare cupressum, / ad tempus di-

22. «No sea que, extendido junto con mi panegirista en una caja tapada, me lleven a la calle donde se vende el incienso, los perfumes y la pimienta, y todo lo que se envuelve con los malos libros.» 23. "Son provechosas para pobres y ricos, para niños y viejos, / todas las cosas que contiene este libro.» 24. "Lo que es igualmente provechoso para pobres y ricos, si se descuida, será igualmente perjudicial para niños y viejos».

25. «Nadie habrá, en fin, que, leído el libro con frente serena, / no pueda sacar ejemplos útiles.» 26. "Ojalá mi señor, Faustino, me lea con frente serena / y acoja mis bromas con el oído acostumbrado.» 
cit frater et omne meus», ${ }^{27}$ que alude directamente al Arte poética de Horacio, con calco textual y en parte métrico (vv. 19-20): et fortasse cupressum / scis simulare, ${ }^{28}$ donde se critica a los malos poetas que se van por las ramas introduciendo descripciones que entorpecen el desarrollo del tema, igual que el pintor que dibuja un ciprés en una escena de naufragio: rompe la regla de oro del arte, unidad y sencillez. Diego López, en cambio, «todo lo dice ad tempus»; o, en palabras de Juan Luis de la Cerda, «muy a propósito». Esto es, todo lo que dice viene siempre a cuento.

Los versos 11-12, «Pone supercilium, lector, cum legeris, ergo; / perlege, sunt creta cuncta notanda quia», ${ }^{29}$ resultan especialmente interesantes, pues el hexámetro recoge la consabida invitación al lector a leer el libro con buen talante (captatio benevolentiae). Tomás López toma de Marcial la imagen metaliteraria del ceño fruncido del censor severo y la invitación a relajarlo (I 4, 1-2): Contigeris nostros, Caesar, si forte libellos, / terrarum dominum pone supercilium. ${ }^{30}$ Esta juntura pone supercilium tuvo éxito entre los autores que debían justificar ante el lector que no cultivaran algunos de los géneros literarios 'serios', como demuestra su uso en Ausonio ${ }^{31}$ o en los Priapeos. ${ }^{32}$ Nebrija, en su Comentario al Carmen Paschale de Sedulio, ${ }^{33}$ comenta así la juntura: Pone supercilium] id est, fastum vel potius gravitatem et severitatem. Vergilius sive ille est Ovidius in Priapeia: 'Conveniens Latio pone supercilium. Vnde et 'superciliosos' appellat Seneca 'tristes et severos alienae vitae censores. ${ }^{34} \mathrm{Al}$ tiempo, en el pentámetro del verso 13, el autor echa mano del conocido adagio creta notanda que remonta a Horacio (Sat. II 3, 246, Sanin creta an carbone notandi?), ${ }^{35}$ y luego recrean Persio (V 108, illa prius creta, mox haec carbone notasti? $)^{36}$ y Marcial (XII 61, 9-11, qui carbone rudi putrique creta scribit carmina, quae legunt cacantes. Frons haec stigmate non meo notanda est). ${ }^{37}$ Igualmente recoge Erasmo este adagio en su vasto repertorio. ${ }^{38}$

27. «En este libro el autor no se ocupa de remedar un ciprés, / y mi hermano todo lo dice en sazón.»

28. "Quizás sepas también remedar un ciprés.»

29. «Depón, pues, el ceño, lector, cuando lo leas; / léelo entero, porque todo es digno de marcar con tiza.»

30. «Si acaso, César, llegas a tocar mis libritos, / depón el ceño dueño del mundo».

31. Ausonio IX 2, 1-2, Carminis incompti tenuem lecture libellum / pone supercilium.

32. Priapeos 1, 1-2 Bücheler, Carminis incompti lusus lecture procaces, I conveniens Latio pone supercilium.

33. Cf. Yarza Urquiola (2011: 84).

34. "Pone supercilium] 'altivez', o mejor 'gravedad' y 'severidad'. Virgilio, o tal vez Ovidio, en los Priapeos: conveniens Latio pone supercilium; de donde también superciliosos llama Séneca [Ep. 123, 11] a los «tristes y severos censores de la vida ajena.»

35. "iLos marcamos con tiza, como sanos, o con carbón?"

36. "¿Señalaste aquellas cosas (las que hay que hacer) con la señal blanca de la greda y estas (las que hay que evitar) con el carbón?»

37. "(Un poeta borracho), que, con un trozo de carbón o con tiza sucia, / escribe poemas que leen los que cagan. Esa frente tuya no ha de ser marcada por mi estigma.»

38. Cf. Des. Erasmus Rotterodamus, Adagiorum chiliades quattuor, Secundus Tomus, Basileae, ex officina Frobeniana, 1540, Chiliadis Primae Centuria V, LIII, "Creta notare, Carbone nota- 
Nuevamente Tomás López pudo oír la explicación de este adagio de boca de su propio hermano en sus clases, o bien leerlo en su comentario a Pers. V 108:

Nótase aquellas primeras, que son las (cosas) buenas y honestas, con tierra blanca, que es con greda, después notase estas postreras, que son las que habemos de huir, las malas y deshonestas, con carbón, y señal negra. Porque cuando votaban antiguamente, si el reo merecía muerte, echaban una piedra negra, y si le daban por libre, ponían una piedra blanca. De manera que las cosas buenas se seńalaban con piedras blancas, y si eran malas, con piedra negra.

El verso 13, "In Creta Alciatus fuerat laberinthus ut alta, / Daedalus ast frater iam patefecit eum», ${ }^{39}$ es una clara reelaboración de Aen. V 588, Vt quondam Creta fertur labyrinthus in alta ${ }^{40}$ hexámetro con el que Virgilio introduce el símil en el que compara la evolución de la caballería de Ascanio en los juegos ecuestres de las honras fúnebres de Anquises con el inextricable laberinto de Creta. Con la alusión a la leyenda de Dédalo y el Laberinto Tomás López trata de reflejar, con una imagen potente, preñada de simbolismo, la labor hermenéutica que su hermano realizó desvelando los arcanos de los emblemas de Alciato.

Aquí, de nuevo Tomás López se pudo proveer del magisterio de su hermano; en concreto del Comentario a las obras de Virgilio, donde Diego López, a propósito de Aen. V 588, comenta: «El laberinto de Creta, tan nombrado de los poetas, edificó aquel muy famoso Dédalo, que estaba tan ciego con las paredes, y trastocadas puertas, que el que una vez entraba en él no podía salir». Sin duda, con la cita de Virgilio, Tomás López hace un guiño a una de las obras comentadas por su hermano, la Eneida de Virgilio, pero, además, con la ecuación Dédalo = Diego López, y sobre todo con la ecuación Laberinto = Alciato, hace un doble guińo a la propia obra de Alciato, primero al Emblema 12 (lema: Non vulganda consilia ducum), donde, a propósito del emblema del Minotauro, comenta Diego López (1615, p. 51v):

Llamaron a esta cárcel 'labyrintho', que significa cosa oscura y enredada, de donde quedó el adagio labyrinthum, el cual se dice cuando en alguna cosa hay una gran dificultad, y está enredada y confusa.

Pero más determinante es el guiño al Emblema 96 de Alciato (lema: Doctorum agnomina) donde Alciato se hace eco de la antigua costumbre universitaria de motejar a los profesores según sus defectos a la hora de explicar las lecciones. Así, llamaban 'Canon', al que explicaba los pasajes fáciles y claros; 'Meandro', al que se repetía demasiado; 'Espada' al que abrevia y (a)corta mucho sus expli-

re», p. 176; cf. Emanuele Lelli, Erasmo da Rotterdam. Adagi, Milano: Bompiani, 2013, 480-481, Centuria V, $\$ 454$.

39. "Fue Alciato como el laberinto en la alta Creta, / pero mi hermano, cual Dédalo, ya lo desveló.»

40. "Como cuentan que antańo fue el laberinto en la alta Creta.» 
caciones... y al oscuro y confuso, "Laberinto» (vv. 7-8): Obscurus et confusus, ut Pico fuit, / Labyrinthus appellabitur. ${ }^{41}$ Diego López comenta así estos dos versos (p. 247r): "(obscurus et confusus) El oscuro y confuso, (ut Pico fuit) como fue Pico, (appellabitur Labyrinthus) llamarase 'laberinto', el qual tenia muchas puertas, y tan confusas, que era difficultosa la salida». Esto es, si en el duelo de rivalidad Diego López vs. Alciato, Tomás López moteja a su hermano de 'Dédalo', apodo sin duda encomiástico, a Alciato, en cambio, le propina una ácida pulla con uno de sus propios motes, 'Laberinto'.

En definitiva, Tomás López, con este epigrama, nos brinda una interesante muestra del llamado "latín de laboratorio», donde contamina, con habilidad, diversas fuentes clásicas: Horacio, Marcial, Persio, Catulo, Virgilio; pasajes de poetas romanos que Tomás López a buen seguro oyó de boca de su hermano en sus clases, o leyó en sus Declaraciones. Con estas citas rinde homenaje a su hermano y a las obras comentadas por su hermano: Virgilio, Persio y Alciato. Si bien es cierto que, por estos dos únicos epigramas, Tomás López no tiene cabida en el Parnaso de los grandes humanistas neolatinos, sí que se hizo, al menos, un hueco, con todo derecho, creemos, en el altar de la Piedad.

Acaso aquí deberíamos poner el punto y final al presente trabajo, si no fuera porque no hace mucho dimos con un nuevo epigrama preliminar que conecta plenamente con lo hasta ahora visto.

Los seis poemas preliminares que figuraban en la editio princeps de la Declaración magistral de las Emblemas de Andrés Alciato (1615) fueron suprimidos en las nuevas ediciones del siglo XVII, todas ellas salidas en Valencia, sucesivamente en 1655,1670 y 1684 . No obstante, en la edición de $1655,{ }^{42}$ figuran tres poemas preliminares: dos de ellos son los dos primeros sonetos castellanos de la editio princeps, ${ }^{43}$ el tercero es un epigrama en latín, pero no el original de fray Tomás López, sino otro compuesto por el canónigo valenciano José Campos, que fue profesor de Prosodia, y más tarde catedrático de Retórica en la Universidad de Valencia..$^{44}$ Entre otras cosas, José Campos publicó en 1675 una Prosodia latina, y en 1660, en Valencia, una edición propia de los Emblemas de Alciato con notas latinas, ${ }^{45}$ que, en último término, no parece sino una labor hecha a partir de esa

41. "Al oscuro y confuso, como fue Pico, se le motejará Laberinto».

42. Declaración magistral sobre las Emblemas de Andrés Alciato, año 1655 con licencia, en Valencia, por Gerónimo Villagrasa, en la calle de las Barcas. A costa de Claudio Macé, mercader de libros, junto al Colegio del Señor Patriarca. Existe edición facsímil de Duncan Moir, ed., Menston, Yorshire: Scolar Press, 1973.

43. En concreto, los sonetos de Francisco Cevallos y de Antonio de la Baria y Cangas.

44. Breve reseña sobre la vida y obras de José Campos en Fuster (1827: 267).

45. Andreae Alciati Emblemata quae singula concinnis inscriptionibus, imaginibus, ac caeteris, quae ad ornatum et castigationem pertinent, illustrantur. Editio novissima, a Iosepho Campos, presbytero, in Academia Valentina publico Prosodia facultatis Professore, copioso indice aucta, solertique labore castigata. Año 1660, Valentiae, per Hieronymum Vilagrasa, in vico Scapharum, expensis Claudii Macè. Pedro F. Campa (1990: 34) documenta la existencia de un ejemplar de esta rara edición 
edición de 1655 de la Declaración de Diego López, ya que se utilizan los mismos grabados para los emblemas, aunque añadiendo breves comentarios en latín a cada emblema, que remiten puntualmente a las declaraciones hechas por López. ${ }^{46}$

José Campos, cuya mano puede que esté detrás de esta primera edición valenciana de 1655 (y por ende del interés por Alciato en el reino de Valencia), ${ }_{4}^{47}$ rescató dos sonetos de la editio princeps que elogian la labor de Diego López como comentarista de Alciato, y sustituyó el epigrama latino de Tomás López, demasiado personal y efusivo con Diego López (amore pio), por un nuevo epigrama latino, salido de su propia pluma y centrado exclusivamente en Alciato. Aun así, José Campos se inspira, a todas luces, en el epigrama de Tomás López, pero suprime la idea-fuerza de la claridad (que solo tenía sentido con la labor declaratoria de Diego López), e insiste sobre todo en la moralidad y la utilidad de la obra.

temprana en los fondos de la Hispanic Society of America. Existen ejemplares de esta primera edición en la Biblioteca Nazionale Centrale de Roma, en la Biblioteca Nacional de Cuba "José Martí», y, según el Catálogo Colectivo del Patrimonio Bibliográfico Español, en el Seminario Diocesano de Segovia y en los fondos de la Biblioteca del Museo del Prado. Fue de nuevo editado por el mismo editor en 1676 en Valencia, apud haeredum Hieronymi Vilagrasa, iuxta Molendinum de Rovella, expensis haeredum Hieronymi Vilagrasa. De esta segunda edición, según el CCPB, existen ejemplares en la Universidad de Barcelona, CRAI Biblioteca de Reserva, en la Biblioteca Pública Episcopal del Seminario de Barcelona (2 ejemplares), en la Biblioteca Municipal Serrano Morales de Valencia, y en la Universidad Complutense de Madrid, Biblioteca Histórica Marqués de Valdecilla. Según el CCPB, en la Biblioteca Pública del Estado en Palma de Mallorca hay un ejemplar fechado en 1654 (?). La directora de dicha biblioteca, María de Lluc Alemany —a quien agradecemos su amable gestión — nos ha confirmado el dato, pero no hemos podido examinar in situ el ejemplar. F. Campa (1990: 33) recoge una edición latina de los Emblemas de Alciato impresa en Valencia en 1654, citada por Karl L. Selig (1955: 359), pero no atribuye autoría de la edición. 46. En los preliminares, además de un epigrama latino salido de su pluma exhortando al lector a la lectura del libro, José Campos recupera la idea original de Diego López de invitar a discípulos suyos a componer poemas encomiásticos a su maestro, y se incluyen así tres epigramas latinos y una décima castellana, a saber: "Epigrama del noble Lorenzo de Cardona, in sui Magistri Campos encomium»; «Epigrama del noble Marco Antonio Sisternes, in sui praeceptoris Campos laudem»; «Epigrama de Luis Alexandre, civis, in sui Magistri Campos laudem»; «Dezima de Don Juan Rafael de la Torre y Orumbella, a su maestro Campos». Dicha práctica, que viene a subrayar el carácter pedagógico del libro, ya se había dado en la reedición de otra obra de Diego López, el Commento en defensa del libro quarto del arte de Grammatica del Maestro Antonio de Nebrissa (Salamanca, 1610), que fue dado de nuevo a la estampa en Madrid en 1652 bajo un nuevo título, Comento sobre el Syntaxis del arte de gramatica, con un tratado de las figuras y muchas frases, sacadas de los autores latinos, para entender, escribir y hablar la lengua latina con propiedad y elegancia, y con algunos cambios en el texto y en los preliminares. Entre las novedades, al menos en el ejemplar custodiado en el fondo antiguo de la Universidad de Sevilla (signatura: A 148/021), figura un epigrama laudatorio latino (20 vv.) de Juan Rodríguez de Molina, posiblemente discípulo de Diego López durante su estancia como profesor en Mérida. De nuevo reaparecen los consabidos tópicos de la captatio benevolentiae y exhortación al lector a leer la obra, cuya erudición se encomia, junto con los conocidos calcos textuales y contextuales de autores clásicos latinos (fronte serena, v. 1; rumpe moras, v. 3; tolle supercilium, v. 5; creta... nota, v. 16; dignissima cedro, v. 17).

47. De confirmarse la edición latina de 1654 (véase nota 45), esto demostraría el interés temprano de José Campos por los emblemas de Alciato y respaldaría su autoría en la reedición valenciana de la de Diego López de 1655, intuida por el poema preliminar suyo y por el parentesco entre los grabados de los emblemas de ambas ediciones. 
La deuda con su predecesor es clara desde el arranque mismo del epigrama, especialmente en los versos 3-6: Aeterna cedro fulgent me iudice digna, I quandoquidem cunctis commoda multa ferunt. / Istud opus pueros recreat, iuvenesque, senesque, / et magna cunctos utilitate replet; ${ }^{48}$ donde Campos mantiene la imagen del cedro, símbolo de eternidad de la obra literaria, y repite la idea del provecho universal de su contenido. No falta tampoco un guiño a Alciato en la parte central del epigrama, entre los versos 7-10: Detinet hoc pueros dum iuglans fallit amara ${ }^{49}$ / tessera dum iuvenes detinet arcte ${ }^{50}$ levis, / delectatque senes, ne segnes chartula picta / detineat, pellens otia prava virum ${ }^{51}$; en los que de manera transparente se reelaboran los dos primeros hexámetros de la conocida dedicatoria de Alciato al humanista alemán Conrad Peutinger, el de la famosa Tabula Peutingeriana:

Dum pueros iuglans, iuvenes dum tessera fallit, detinet et segnes chartula picta viros... ${ }^{52}$

Tras el homenaje a Alciato, José Campos, como hizo antes Tomás López, pasa a exhortar al lector a una rápida y total lectura del libro, que, sin duda, le resultará provechosa (vv. 11-16):

Quare si sana frueris ratione repente, candide lector, opus perlege mente cito.

Seu iuvenisve senex, tenerae vel flore iuventae, roribus his Pindi prolue labra tua.

Hoc opus amplexare, preco; tibi commoda Semper mille dabit. Capias emolumenta. Vale. ${ }^{33}$

Llegados a este punto, pasemos, pues, a la edición completa y a la correspondiente traducción al castellano de este epigrama latino de José Campos:

48. «(Los versos que este libro contiene) los compuso Alciato con docta melodía. / Brillarán, a mi juicio, dignos de eterno cedro, / pues dicen muchas cosas provechosas para todos. / Esta obra recrea a los niños, a los jóvenes y a los viejos, / y colma a todos con gran utilidad.»

49. amara emendavimus : amata editio 1655.

50. arcte emendavimus: arte editio 1655.

51. «Esta obra entretiene a los niños, mientras que la bellota amarga los distrae, / a los jóvenes, mientras que el dado pulido los distrae mucho, / y deleita a los ancianos, para que el naipe no los entretenga, / ociosos, expulsando los malos ocios de los hombres.»

52. "Mientras la nuez entretiene a los niños, el dado a los jóvenes, / y los naipes distraen a los hombres ociosos, / (hemos elaborado nosotros, en horas festivas estos emblemas...).»

53. «Por eso, cándido lector, si de repente gozas de sano juicio, / date prisa y lee el libro entero. / Seas joven o viejo, o estés en la flor de la tierna juventud, / moja tus labios en estas aguas del Pindo. / Acoge, te lo ruego, esta obra; te dará siempre / mil utilidades. Que te aproveche. Adiós.» 
Iosephi Campos, diaconi, in Academia Valentina publici Prosodiae facultaTIS PROFESSORIS, AD LECTOREM EPIGRAMMA

Quae docto Alciatus cecinit modulamine metra, gaudia Musarum, continet istud opus.

Aeterna cedro fulgent me iudice digna, quandoquidem cunctis commoda multa ferunt.

Istud opus pueros recreat, iuvenesque, senesque, et magna cunctos utilitate replet.

Detinet hoc pueros dum iuglans fallit amara, tessera dum iuvenes detinet arcte levis,

delectatque senes, ne segnes chartula picta detineat, pellens otia prava virum.

Quare si sana frueris ratione repente, candide lector, opus perlege mente cito.

Seu iuvenisve senex, tenerae vel flore iuventae, roribus his Pindi prolue labra tua.

Hoc opus amplexare, preco; tibi commoda semper mille dabit. Capias emolumenta. Vale.

De José Campos, diácono, profesor ordinario de la cátedra de Prosodia en LA Universidad de VAlencia, al LECTOR

Los versos que este libro contiene, gozos de las Musas, los compuso Alciato con docta melodía.

Brillarán, a mi juicio, dignos de eterno cedro, pues dicen muchas cosas provechosas para todos.

Esta obra recrea a los niños, a los jóvenes y a los viejos, y colma a todos con gran utilidad.

Esta obra entretiene a los nińos, mientras que la bellota amarga los distrae, a los jóvenes, mientras que el dado pulido los distrae mucho,

y deleita a los ancianos, para que el naipe no los entretenga, ociosos, expulsando los malos ocios de los hombres.

Por eso, cándido lector, si de repente gozas de sano juicio, date prisa y lee el libro entero.

Seas joven o viejo, o estés en la flor de la tierna juventud, moja tus labios en estas aguas del Pindo.

Acoge, te lo ruego, esta obra; te dará siempre mil utilidades. Que te aproveche. Adiós.

Dada la tradición retórica en España, ${ }^{54}$ el surgimiento de esta poesía latina de preliminares, que en la primera mitad del siglo XVII llegó a constituir un géne-

54. Sobre la importancia que tuvo la Retórica en el ámbito de las enseñanzas durante los siglos XVI y XviI, cf. López Grigera (1994: 49-60); Merino (1992); Sánchez Salor y Chaparro (1984: 33-160; 179-372); Rico Verdú (1973: 73-245); Martí (1972). 
ro particular dentro de la producción literaria latino-humanística, es fácil de entender; sobre todo, por el papel fundamental que desempeñaba la enseñanza de la Retórica dentro de los studia humanitatis. Falta acaso un estudio que aborde cumplidamente las estrechas relaciones que se prevén entre la composición de esta poesía de preliminares que encabezaba los impresos del Siglo de Oro y los ejercicios retóricos de composición literaria que se impartían dentro del programa para la enseńanza de la Retórica en la época; un estudio que reúna, asimismo, un corpus exhaustivo de aquellas composiciones preliminares que responden a este patrón didáctico. 


\section{Bibliografía}

ArtazA, Elena, «El ars narrandi en los Progymnasmata de Antonio Lulio», en Homenaje a Eugenio Asensio, Madrid, Gredos, 1988, 41-55.

—, Las retóricas barrocas (1600-1650): notas introductorias, en Estudios de filología y retórica en homenaje a Luisa López Grigera, coords. E. Artaza, J. Durán, C. Isasi Martínez, J. Lawand, V. Pineda González, F. Plata Praga, Universidad de Deusto, 2000, 45-66.

Asís Garrote, María Dolores de, "Los Studia Humanitatis y las formas literarias del Renacimiento español (Análisis de un «Prólogo» del comendador griego)», ed. Manuel García Martín, Estado actual de los estudios sobre el Siglo de Oro: Actas del II Congreso Internacional de Hispanistas del Siglo de Oro (2. 1990), vol. 1 (1993), 153-160.

Campa, Pedro F., Emblemata Hispanica. An Annotated Bibliography of Spanish Emblem Literature to the Year 1700, Durham and London, Duke University Press, 1990.

Fernández de Avellaneda, Alonso, Segundo tomo del ingenioso hidalgo don Quijote de la Mancha, ed. Luis Gómez Canseco, Madrid, Real Academia, 2014.

Fortuny Previ, Filomena, «La Declaración magistral de Diego López a las Sátiras de Persio: Precisiones lingüísticas (I)», Myrtia, 14 (1999), 153-170.

—, «La Declaración magistral de Diego López: Cuestiones de Realia (II)», en Historia y Humanismo. Homenaje al profesor Pedro Rojas Ferrer, Murcia, Universidad de Murcia, 2000, 321-337.

—, "Presencia de los humanistas en el comentario de Diego López a Persio», ed. Miguel Rodríguez-Pantoja, Las raíces clásicas de Andalucía. Actas del IV Congreso Andaluz de Estudios Clásicos (Córdoba 18-20 de septiembre 2002), Córdoba, Publicaciones Obra Social y Cultural Cajasur, vol. 2 (2006a), 717-731.

—, "La traducción de Diego López de las Sátiras de Persio», en Miguel Rodríguez-Pantoja, ed., Las raíces clásicas de Andalucía. Actas del IV Congreso Andaluz de Estudios Clásicos (Córdoba 18-20 de septiembre 2002), Córdoba, Publicaciones Obra Social y Cultural Cajasur, (2006b), vol. 2, 733-748.

Fuster, Justo Pastor, Biblioteca valenciana de los escritores que florecieron hasta nuestros dias, tomo I: Los autores hasta el año 1700, Valencia, Imprenta y Librería de José Ximeno, 1827.

Güell, Mónica, «Paratextos de algunos libros de poesía del Siglo de Oro. Estrategias de escritura y poder», eds. María Soledad Arredondo, Pierre Civil y Michel Moner, Paratextos en la literatura española: Siglos XV-XVIII, Madrid, Casa de Velázquez, 2009, 19-35.

IzQuierdo IzQuierdo, José Antonio, «Diego López», ed. Juan Francisco Domínguez, Diccionario Biográfico y Bibliográfico del Humanismo Español (siglos XV-XVII), Madrid, Ediciones Clásicas, 2012, 495-497.

López Grigera, María Luisa, «Notas sobre Progymnasmata en la España del siglo XVI», eds. José María Maestre Maestre, Joaquín Pascual Borea, $\mathrm{Hu}$ - 
manismo y pervivencia del mundo clásico (Alcañiz, 8 al 11 de mayo de 1990), vol. 2, Cádiz, Servicio de Publicaciones de la Universidad de Cádiz-Instituto de Estudios Turolenses (CSIC), 1993, 585-590.

-, La retórica en la España del siglo de oro: teoría y práctica, Salamanca, Ediciones Universidad de Salamnaca, 1994.

Maestre Maestre, José María, «Sistema, norma y habla y creatividad literaria latino-tardía", Actas del I Congreso Andaluz de Estudios Clásicos, Jaén, Excma. Diputación Provincial-Instituto de Estudios Giennenses (C.S.I.C.), 1982, 260-267.

—, «La influencia del mundo clásico en el poeta alcañizano Juan Sobrarias: estudio de sus fuentes literarias», Anales de la Universidad de Cádiz, 2 (1985), 325-340.

—, Poesías varias del alcañizano Domingo Andrés, Teruel, Instituto de Estudios Turolenses (C.S.I.C.), 1987.

-, El humanismo alcañizano del siglo XVI. Textos y estudios de latín renacentista, Cádiz, Servicio de Publicaciones de la Universidad de Cádiz-Instituto de Estudios Turolenses (CSIC)-Excmo. Ayuntamiento de Alcañiz, 1990.

Marsá, María, "Poesía laudatoria castellana en impresos del Siglo de Oro», en José Luis Girón Alconchel et alii, eds., Estudios ofrecidos al Prof. José Jesús de Bustos Tovar, Madrid, Editorial Complutense, 2003, II, 1253-1272.

MarTí, Alanís, La preceptiva retórica española en el Siglo de Oro, Madrid, Gredos, 1972.

Merino Jérez, Luis, «Nota a la poesía latina del humanista Diego López: la Epistola de laudibus Valentiae ordinis Alcantaresis y otros textos», Anuario de estudios filológicos, 10, Cáceres, 1987, 229-243.

—, La pedagogía en la retórica del Brocense. Los principios pedagógicos del Humanismo renacentista (natura, ars y exercitatio) en la Retórica del Brocense (memoria, methodus y analysis), Cáceres, Universidad de Extremadura, 1992.

—, "La poesía latina de Diego López de Valencia de Alcántara», eds. César Chaparro Gómez, Manuel Mañas Núñez y Delfín Ortega Sánchez, 'Nulla dies sine linea'. Humanistas extremeños: de la fama al olvido, Cáceres, Universidad de Extremadura, 2009, 219-241.

Rico Verdú, José, La Retórica española en los siglos XVIy XVII, Madrid, CSIC, 1973. Sánchez Salor, Eustaquio y Chaparro Gómez, César, Francisco Sánchez de las Brozas, Obras I, Escritos retóricos, Cáceres, Institución Cultural «El Brocense», 1984.

Yarza Urquiola, Valeriano, Aelii Antonii Nebrissensis Gramm. Opera. Comentario al 'Carmen Paschale' y a dos himnos de Sedulio, Salamanca, Ediciones Universidad de Salamanca, 2011. 
